\title{
Improving Early Warning Systems with Categorized Course Resource Usage
}

\author{
R. Joseph Waddington \\ College of Education \\ University of Kentucky \\ SungJin Nam \\ School of Information \\ University of Michigan \\ Steven Lonn \\ Digital Education \& Innovation \\ University of Michigan \\ Stephanie D. Teasley \\ School of Information \\ University of Michigan \\ steasley@umich.edu
}

\begin{abstract}
Early Warning Systems (EWSs) aggregate multiple sources of data to provide timely information to stakeholders about students in need of academic support. There is an increasing need to incorporate relevant data about student behaviours into the algorithms underlying EWSs to improve predictors of student success or failure. Many EWSs currently incorporate counts of course resource use, although these measures provide no information about which resources students are using. We use seven years of data from seven core STEM courses at a large university to investigate the associations between student use of categorized course resources (e.g., lecture or exam preparation resources) and their final course grade. Using logistic regression, we find that students who use exam preparation resources to a greater degree than their peers are more likely to receive a final grade of B or higher. In contrast, students who use more lecture-related resources than their peers are less likely to receive a final grade of $B$ or higher. We discuss the implications of our results for developers deciding how to incorporate categories of course resource usage data into EWSs, for academic advisors using this information with students, and for instructors deciding which resources to include on their LMS site.
\end{abstract}

Keywords: Early warning systems, academic advisors, learning management systems, course resources, student grades 
(2016). Improving early warning systems with categorized course resource usage. Journal of Learning Analytics, 3(3), 263-290. http://dx.doi.org/10.18608/jla.2016.33.13

\section{INTRODUCTION}

With the growing interest in learning analytics (LA), colleges and universities are expanding their use and development of systems that aggregate multiple sources of student data to produce insights into student behaviour related to academic success (Campbell, DeBlois, \& Oblinger, 2007; Siemens \& Long, 2011; Johnson, Becker, Estrada, \& Freeman, 2014). Identifying students "at risk" for failing courses and/or dropping out has long been an area of interest predating the term learning analytics (see Braxton, 2000). However, research in higher education is moving away from solely identifying the lowest performing students to instead using "big data" to describe and predict performance and learning outcomes for all students (Siemens \& Long, 2011). In particular, researchers and practitioners are asking, "What data is actionable for all students?" Once identified, "What actions are facilitated by the presentation of the data?" and "How can the data be represented in a manner that can reasonably interpreted and acted upon to improve teaching and learning outcomes?"

One class of these systems that have come from LA work are Early Warning Systems (EWSs), also called Early Alert Systems (EAS). Researchers and commercial vendors are designing EWSs to provide information to students, instructors, advisors, and/or other intermediaries for the purposes of quickly and easily identifying students in need of academic support (Beck \& Davidson, 2001; Macfadyen \& Dawson, 2010). As EWSs become an integrated tool within educational technologies, researchers and developers must begin to evaluate carefully the components underlying the algorithms driving these systems (Ferguson, 2012).

Both researchers and commercial vendors of web-based technologies, particularly learning management systems (LMSs), have become particularly interested in creating new tools or system add-ons that collect student activity data to utilize for assessing student risk factors and providing actionable information. Given the consistency in the types of data generated by LMSs, similar kinds of data elements comprise the algorithms and categorization schemes behind EWSs (Sharkey \& Ansari, 2014). Most systems rely primarily on student grade information and login frequency; developers typically display these data in relation to relative class performance. However, we are now at a point in time where it is possible to investigate which additional data points can further explain the variation in student course outcomes and thereby recognize both successful and unsuccessful individual-specific behaviours to provide more personalized feedback when designing interventions.

In this paper we use seven years of data from seven core science, technology, engineering, and mathematics (STEM) courses to investigate how additional data generated by students' course LMS resource use can be incorporated into an EWS to refine its' explanatory and classification power. We focus on these STEM courses because they represent the main "gateway" courses in these disciplines where undergraduate students experience their first indication of whether or not they are likely to succeed in majoring in STEM coursework. Specifically, we investigated student use of the various types of course resources that instructors typically make available in their course website. 
(2016). Improving early warning systems with categorized course resource usage. Journal of Learning Analytics, 3(3), 263-290.

http://dx.doi.org/10.18608/jla.2016.33.13

We utilized an existing EWS, called Student Explorer (Krumm, Waddington, Teasley, \& Lonn, 2014), which draws student activity from data captured by the university's LMS to conduct our study. The current form of Student Explorer provides academic advisors with real-time data about student grades and LMS login frequency. However, advisors may be able to target their interventions more effectively if the EWS included data about whether or not students are accessing and using important course resources, such as practice exams or lecture notes. Moreover, the results of this study can provide important information to instructors about the course resources they include in an LMS, as well as inform EWS developers about the information they should include in data analyses and display via dashboards.

Two primary research questions guided our work:

(RQ1) "What is the association between students' use of four types of course LMS resources and the likelihood that a student receives a final course grade of A or B in a core STEM course versus a C?"

(RQ2) "Are there similarities or differences in the associations between students' course resource use based on type and final course grades across multiple courses?"

Understanding the association between student use of course resource types and student grades will shed light on whether or not particular course resource data can be important indicators of course performance and how these data could be incorporated into an EWS such as Student Explorer. We outline the current landscape of the development of EWSs within the LA field before describing Student Explorer. Then, we detail the course resource LMS data, methods, analyses, and results of this study. We conclude the paper by discussing the implications of the results in the context of general EWS development and give consideration to the next steps for incorporating student resource use into Student Explorer.

\section{CONCEPTUAL FRAMEWORK}

\subsection{Early Warning Systems Research}

Early academic analytics initiatives in higher education aimed to predict which students were at risk of academic difficulty (Campbell \& Oblinger, 2007). Recent research in this area has differentiated academic analytics, employing data to support operational and financial decision making, from learning analytics, using data to understand and optimize student learning and the environments in which it occurs (SoLAR, n.d.; van Barneveld, Arnold, \& Campbell, 2012). Optimizing the learning environment in higher education, particularly across students' concurrent course loads, includes presenting patterns and indicators of student behaviour to intermediaries (e.g., academic advisors and coaches) who can act upon such information (Duval, 2011; May, George, \& Prévôt, 2011). Our prior work has focused on leveraging a learning-analytics-powered early warning system, Student Explorer, to help academic advisors quickly identify students in need of academic support and allow these professionals to engage 
(2016). Improving early warning systems with categorized course resource usage. Journal of Learning Analytics, 3(3), 263-290. http://dx.doi.org/10.18608/jla.2016.33.13

in sense-making activities that support subsequent actions (see Krumm et al., 2014; Lonn, Aguilar, \& Teasley, 2015).

Early warning systems (EWSs) use historical and formative educational data to identify students who might be at risk of academic failure, often doing so in near real time. To be valuable for informing academic interventions, Dringus (2012) argues that student data must be "measurable, visible, and transparent" (p. 98). Building on earlier proofs-of-concept that use such student data (e.g., Macfadyen \& Dawson, 2010; Morris, Finnegan, \& Wu, 2005), Course Signals was one of the first EWSs broadly deployed to use students' formative course performance, online learning management system (LMS) activity, prior academic history, and demographics to indicate the likelihood of academic failure to instructors (Arnold, 2010; Arnold \& Pistilli, 2012). Jayaprakash and colleagues created the Open Academic Analytics Initiative (OAAI), which sought to create an open predictive model for use in EWSs based on Campbell's (2007) original model for Signals (Jayaprakash, Moody, Lauria, Regan, \& Baron, 2014). Testing this model first at Marist College and subsequently at four small to mid-size institutions, the investigators found that the model was effective in large lecture-style courses with enrollments of $100+$ students, but the "value added" for an instructor was harder to discern in smaller class sizes. Additionally, Jayaprakash et al. (2014) uncovered a general trend where some students improved after receiving one "treatment" (e.g., being contacted by the instructor based on the predictive model) and another group of students who did not improve regardless of the number of "treatments" received. Finally, the investigators indicate that EWSs that utilize models based on blended courses do not translate well to fully online course contexts.

This dichotomy in EWS effectiveness depends on whether recent investigations account for course modality. In online contexts, particularly where LMS activity is translated into "time on task" variable constructs, an EWS can effectively characterize a student's current learning performance (Hu, Lo, \& Shih, 2014). Further demonstrating this contextual difference, Agudo-Peregrina and colleagues (2014) found an association between LMS interactions and academic performance in online courses, but not in LMSsupported blended courses. The LMS interaction association for the online courses examined by these investigators could be classified by 1 ) agent (student-student, student-teacher, student-system, and student-content), 2) frequency of LMS use, and 3) mode of use (active vs. passive). While some argue that time-on-task is indicative of time spent on learning and is thus of critical concern to all LA initiatives (Kovanović et al., 2015), particularly for EWS implementations, such estimations can artificially smooth over important differences in how LMSs are used in different contexts. For example, Beer, Jones, and Clark (2009) found a strong association between LMS activity and course grades across five years of LMS data for blended courses, but instructor use was a significant mitigating factor. When the instructor's use of the LMS was "super low," there was no discernable association between LMS usage and grades.

Considering this variability, we first developed Student Explorer to use the data most common across all LMS course websites: grades and logins. Website hit consistency (how regularly a student visits a website between class meetings) is an important indicator that can indicate more interest in a course and better time management skills (Baughter, Varanelli, \& Weisbord, 2003). Student Explorer therefore 
(2016). Improving early warning systems with categorized course resource usage. Journal of Learning Analytics, 3(3), 263-290.

http://dx.doi.org/10.18608/jla.2016.33.13

uses the rank percentile of students' weekly LMS website views (all page views within a course website) to gauge login consistency against all other students in the course. In the study described in this paper, we extend this work by adding another common data element, use of file resources, but do so in an approach that takes advantage of the available metadata for each file. Other EWSs have used counts of file resource uploads and downloads in their algorithms and found that such activity can explain more variation of individual grades than website logins (e.g., Braender \& Naples, 2013). Our belief is that a more detailed approach that leverages file metadata can extend the utility of EWSs beyond retention (Arnold \& Pistilli, 2012) and enrollment (Harrison, Villano, Lynch, \& Chen, 2015) outcomes to provide avenues to maximize learning for all students. Below, we give a detailed description of the development of Student Explorer before describing our motivation for conducting this study and expanding the capabilities of this EWS.

\subsection{Development of Student Explorer}

Student Explorer is an EWS that originally provided near real-time data from the LMS at a large research university to support the existing work of academic advisors in the STEM (Science, Technology, Engineering, and Mathematics) Academy (Krumm et al., 2014). The aim of the STEM Academy is to increase the academic success of historically underrepresented students in STEM fields through a holistic student development program. Researchers and the STEM Academy's academic advisors and leaders developed Student Explorer through a two-year collaborative effort using principles of designbased research (Cobb, Confrey, diSessa, Lehrer, \& Schauble, 2003; Krumm et al., 2014). Student Explorer now also serves staff members in Summer Bridge, probation, and general engineering advising roles across campus, annually tracking over 4,500 undergraduate students (Lonn et al., 2015).

Prior to Student Explorer, advisors relied upon students' self-reported grades during face-to-face meetings or instructor-provided midterm progress reports. The infrequency of these meetings and reports, combined with the reliance on self-reported grades, did not allow advisors to intervene in as timely or targeted of a manner as hoped. Therefore, mentors used Student Explorer to more readily identify and engage students in need of academic support in discussions about their ongoing performance (Krumm et al., 2014).

Student Explorer aggregates course grade and LMS site page views for each student for all of their courses. Academic advisors view the aggregated grade and page view data through a variety of visualizations, including within course comparisons of students' performance relative to their peers over the term. Advisors reported the most useful feature of Student Explorer is a three-level classification scheme that combines academic performance and page view data to highlight which students are doing well, having difficulty, or are in immediate need of academic support. The system also allows advisors to drill down in the students' grade data to view performance on individual graded elements, such as homework, quizzes, and exams. However, Student Explorer does not provide information about student use of specific course LMS resources or the potential influence of resource use on grades. See Krumm et al. (2014) for a detailed explanation of the design and development of Student Explorer. 
(2016). Improving early warning systems with categorized course resource usage. Journal of Learning Analytics, 3(3), 263-290. http://dx.doi.org/10.18608/jla.2016.33.13

\subsection{Motivation for Including Course Resource Use in Student Explorer}

The classification scheme and information about a student's developing grade shown by Student Explorer are valuable components for advisors to identify quickly which students are struggling. However, the usefulness of displaying LMS data in an EWS goes well beyond providing a single indicator of student performance. Incorporating additional performance-related LMS data into the EWS would allow advisors or other users to intervene in a more personalized manner.

In their current form, many EWSs rely upon "prediction" models, which combine sources of information about student characteristics and activity-to-date into a measure of how a student is going to do. One of the benefits of Student Explorer is that the system provides information of how the student is currently doing across an array of courses. Part of our challenge, then, is to incorporate various types of information related to student course performance across a diverse set of courses by using a straightforward data mining and modelling approach. Further, the information needs to be interpretable by the intended users. Few EWSs incorporate the course resources that students are "hitting" (viewing, downloading, saving, etc.), and those that do incorporate such information only account for overall file upload and/or download counts (e.g., "RioPACE," Ornelas, Ordonez \& Huston, 2014). Therefore, we investigated the association between categories of course resources and student grades in a single course to first determine whether these data matter. Later, we consider how developers might incorporate and advisors might interpret resource usage data so that it is scalable across courses.

When considering the need to modify the current version of Student Explorer by including information about student use of course resources, we focus on three primary audiences: academic advisors, course instructors, and designers of EWSs. For advisors, having information on resource use helps to provide more concrete information about what students are or are not doing as part of their work for a course. This provides an additional layer of information in the connection between a student's performance and their actual habits/activities. In addition, by understanding more about the resource-use trends displayed by top students in previous iterations of a given course, advisors can have a better benchmark when conversing with current students. That said, we are not studying the possible inclusion of course resource information to distinguish between students performing well; rather, we want to add this component so that students on the margin of receiving a desired versus an undesired final grade can receive more targeted support from advisors to improve their habits and academic performance.

For instructors, investigating some of the patterns of resource use and their correlation with student grades yields information about the purpose and value of various resources. Earlier research on LMS use has shown that the most common instructor behaviour is to provide an increasing number of resources on their course site, often overwhelming students (Lonn, Teasley, \& Krumm, 2011). Providing instructors with information about actual resource use along with the association between student resource use and course performance may allow them to more carefully consider which resources to include (and how they should be integrated) in the LMS. This approach is opposed to an instructor simply including everything that might be useful, relevant, or supplementary to the course content and assessments. This 
(2016). Improving early warning systems with categorized course resource usage. Journal of Learning Analytics, 3(3), 263-290.

http://dx.doi.org/10.18608/jla.2016.33.13

information is also important for those developing LA-based systems, such as EWSs. Developers and researchers can rely upon data-informed decision-making when designing models or including information in a dashboard or other displays that place a premium on parsimony.

\section{DATA AND METHODS}

\subsection{Data Description}

Academic advisors in the STEM Academy primarily focus on providing support for courses in the STEM fields, and first-year students receive the greatest degree of support. Therefore, we focus on seven core first- and second-year courses for students majoring in the STEM fields. These courses include Engineering (two courses), Physics (two courses), and Chemistry (three courses) courses, to which we have assigned course name and number pseudonyms. ${ }^{1}$ Our analysis focuses on all students in these courses, not solely STEM Academy students, such that any observed association between resource use and grades would be reflective of the population of students in the course as opposed to a targeted subset that could skew the results. A brief description of each course is included in Appendix A.

We use student final course grades as our outcome measure of student performance. One of the distinct goals of STEM Academy academic advisors is to help students to obtain an overall grade-point average (GPA) of a 3.0 or higher. The student's GPA is an average of course performance across all courses completed, weighted by the credit hours earned for each course (a typical course at the university is three credit hours). The letter grade (e.g., A, A-, B+, B, etc.) a student receives at the end of a course is converted to a numerical value (e.g., $A=4.00, A-=3.67, B+=3.33, B=3.00$, etc.) to calculate the grade-point average. Therefore, an overall GPA of 3.0 corresponds to an average of a "B" final grade across courses.

We created two distinct outcome measures using final course grades for use in separate analyses. The first outcome is a dichotomous variable to indicate whether a student's final course grade was either an A or B versus a C. Advisors consider any A or B final course grades as "desirable" outcomes while C grades are "undesirable" outcomes, given the overall GPA goal of 3.0 for STEM Academy students. We condensed grades of $A+, A$, and $A$ - into the " $A$ " category and did the same for the " $B$ " and " $C$ " grade categories. ${ }^{2}$ For the second outcome measure, we separate students earning $A$ and $B$ grades to distinguish differences in the associations between course resources and grades between all three groups of students.

\footnotetext{
${ }^{1}$ We considered using data from one additional core chemistry and engineering course each. However, the grade distribution in these courses was such that less than $2 \%$ of students received a " $C$ " or lower final grade.

${ }^{2}$ A final course grade of a B- (2.67) is lower than the overall GPA target of 3.0. However, in several of the introductory STEM courses at the university, the average student experiences what is known as a "grade penalty" due to the difficulty of the course, earning lower than they would in a typical course (see Huberth, Chen, Tritz, \& McKay, 2015). Therefore, we group the Bstudents with the $B+$ and $B$ students throughout our analyses and descriptions of results.
} 
(2016). Improving early warning systems with categorized course resource usage. Journal of Learning Analytics, 3(3), 263-290. http://dx.doi.org/10.18608/jla.2016.33.13

We excluded all individuals receiving a $\mathrm{D}$ or $\mathrm{F}$ final grade in any course from our analyses for two reasons. First, the population of all students enrolled in STEM courses at the university (specific to this university context) is largely a high achieving group. There were only a small number of students receiving a $D$ (poor performance, but still earning credit for the course) or $F$ (failing the course) in each course (ranging from $0.1 \%$ to $6.2 \%$ of students in any one course, see Appendix Table C.1). The small proportions of poorly performing students makes it difficult to disentangle any differential impacts of course resources on the final grades for these low achieving students versus all others. Second, we intend for the results of this study to refine the classification model already in place for the Student Explorer EWS. Added information about the use of course resources will help to classify and highlight to advisors students that are specifically on the margin of receiving a " $C$ " grade in the course (an undesirable grade) compared to a "B" grade (desirable). We could potentially observe positively biased estimates of the associations between course resource use and course grade if the $D$ and $F$ students "dragged down" the " $C$ " students. For students at risk of receiving a D or $F$ in the course, the EWS already alerts advisors about their poor performance by highlighting the student's academic performance on available exam, assignment, or other data before utilizing information about LMS resource use. $^{3}$

We also excluded the few students who withdrew from the course at some point during the semester or received an incomplete final grade (0.9\% to $4.2 \%$ of students across courses, see Appendix Table C.1). We remove these students from analysis for two reasons. First, these students do not receive a letter grade that necessarily reflects course performance (e.g., an incomplete final changed could later be changed to any possible letter grade, depending on performance). Second, because of receiving an incomplete grade in the course or withdrawing, many of these students will not have spent an equivalent amount of time in the course as their peers, leading to differences in exposure to the course resources.

We classified course resources in the LMS by a structure that is adaptable across multiple semesters and courses. We initially created these categories based on data from the CHEM 101 course (see Waddington \& Nam, 2014, where it is referred to as CHEM 100). The course structure and resources used in CHEM 101 remained relatively stable across course sections and semesters. We found the same consistency in the additional six courses we include in this study, as well as those courses having categories of course resources in common with CHEM 100. As a result, we were able to classify the LMS course resources into distinct, replicable groups and look at the impacts of their use on a student's grade across multiple semesters and courses instead of relying upon one semester (when available) or one course-worth of data. We are thus able to draw conclusions about categories of course resources over time and across courses.

\footnotetext{
${ }^{3}$ We display results from our multinomial logistic regression analyses that includes the handful of students receiving a $D$ or $F$ final grade with $\mathrm{C}$ students in Appendix Table C.4. We find no discernible differences in our results from our preferred models where $\mathrm{D}$ and $\mathrm{F}$ students are excluded.
} 
(2016). Improving early warning systems with categorized course resource usage. Journal of Learning Analytics, 3(3), 263-290. http://dx.doi.org/10.18608/jla.2016.33.13

We identified four broader categories of LMS course resources through our classification phase. These categories include course information resources (e.g., syllabus, announcements), lecture-related resources (e.g., notes, discussion), assignment-related resources (e.g., problem sets, experiments), and exam preparation resources (e.g., practice exams). We bundled individual resources into these broader categories by searching across all resources based on specific keywords. While there is some degree of variation in the materials provided for each course and each semester, each course uses some form of lecture or course information materials. ${ }^{4}$ We included the category names and examples of LMS resources as well as further details of our categorization process in Appendix B.

After categorizing the resources within each course into four groups, we next constructed the measures of each student's use of course resources. We calculated each student's percentile rank of course resource use within each resource category compared to their peers' use of the same category of resources in the same course section. The percentile rank measures range from 1 to 99. We chose to use within-course percentile rank for two reasons. First, these course resource use data are highly skewed, so this eliminates outliers who may access materials with far greater frequency than their peers (such as re-opening the same resource multiple times vs. saving and downloading). Second, using a relative measure allows us to combine data from multiple sections and semesters into one model and then make comparisons across semesters within a course and between courses.

Our data contained records of students and course resources spanning three to twelve 16-week semesters (depending on course), from 2007-2014. In total, there were 26,843 students enrolled across these seven courses over seven academic years, with 26,784 students included in our analyses that have a full set of valid covariate measures described in the next section.

\subsection{Estimation Strategy}

We used two versions of a logistic regression model to estimate the association between student course resource use on the likelihood that a student receives a certain final grade. Our first model (1) is a standard logistic regression model where we estimate the likelihood that a student receives an A or B final grade versus a $\mathrm{C}$ in a given course. We estimated separate models for each of the seven courses. Functionally, the logistic regression model takes the following form:

$\ln \left(\frac{\operatorname{Pr}\left[Y_{i}=A \text { or } B\right]}{\operatorname{Pr}\left[Y_{i}=C\right]}\right)=\alpha+\beta_{1}$ CInfo $_{i}+\beta_{2}$ Lect $_{i}+\beta_{3}$ Assign $_{i}+\beta_{4}$ ExamPrep $_{i}+\theta \mathbf{X}_{\mathbf{i}}+\sum_{s=1}^{N} \delta_{s} S_{i}$

In the above equation (1), the probability that a student $i$ receives an A or B ("desired outcome") in a given course versus a C ("undesired outcome") is a function of their within-course percentile rank in the use of four types of course resources (Course Information, Lecture-Related, Assignment-Related, and Exam Preparation). We adjust the estimates of the associations between resource use and final grade by

\footnotetext{
${ }^{4}$ CHEM 202 is a laboratory course that is required when a student enrolls in CHEM 201. The course does not have any exams. PHYS 201 does not have any assignments.
} 
(2016). Improving early warning systems with categorized course resource usage. Journal of Learning Analytics, 3(3), 263-290.

http://dx.doi.org/10.18608/jla.2016.33.13

controlling for a vector of covariates representing the student's demographic and academic background $\left(\mathbf{X}_{\mathbf{i}}\right)$ along with a fixed effect for the semester in which the student was enrolled in the course $\left(S_{i}\right)$.

The student demographic covariates include the student's sex. We use a dichotomous variable indicating the differences in final grade likelihood between females and males. Within the literature on performance in STEM courses (broadly and within the university), there are notable differences in the performances of men and women (Carrell, Page, \& West, 2010; Kost, Pollock, \& Finkelstein, 2009; Hazari, Tai, \& Sadler, 2007). Because prior research has shown that international students are more engaged in educational activities than their American counterparts (Zhao, Kuh, \& Carini, 2005), we also control for citizenship, including individuals who are U.S. citizens, non-citizen permanent residents, and non-U.S. residents. Indirectly, this measure also serves as a proxy for students for whom English is a second language.

Regarding academic background, we control for a student's first-term math course placement. Prior to beginning their studies at the university, students take a math placement assessment that recommends the math course the student takes during their first term. Across the seven courses in our study, 92-99\% of students took the placement assessment and the actual first-term math course taken matched the course placement suggested by the assessment near universally. We created a dichotomous indicator of Calculus I or higher placement (the majority of students placed at this level), versus all lower courses (see Table 2 for details). We included a separate indicator for the 1-7\% of students in a given course who did not take the placement test. We believe that the first-year math placement results are a better indicator of student math ability in the context of STEM course performance within this specific university than SAT or ACT math scores because it largely determines the first math course taken. We also avoid having to convert between SAT and ACT scores or having to adjust these scores as their scales changed over time.

We also control for each student's semester GPA, which we have recalculated after removing the final grade earned in the STEM course that is the subject of analysis. This measure accounts for other contextual factors regarding a student's academic performance during the given semester in which they took the course. For example, a low semester GPA suggests that a student may be struggling academically independent from their performance in a given STEM course.

We included semester fixed effects in our model to account directly for the variation in the distribution of student grades across $\mathrm{N}$ course semesters of available data for each course. Using pooled data across semesters yields a greater degree of consistency in estimating the association between course resources and student grades. In doing so, it is necessary to account for differences in average student performance between semesters through the semester fixed effects. The fixed-effect nature of the semester indicators also controls for unobserved factors between semesters that might influence the association between resource use and student grades. These unobserved factors include semester-tosemester differences in average student ability as well as any instructor-related differences such as the quality of teaching or encouraging the use of specific resources in the LMS. By including semester fixed 
(2016). Improving early warning systems with categorized course resource usage. Journal of Learning Analytics, 3(3), 263-290. http://dx.doi.org/10.18608/jla.2016.33.13

effects, we estimate the within-semester association between a given student's course resource use and the likelihood of receiving a certain course grade after controlling for a host of covariates.

In model $1, \beta_{1}$ through $\beta_{4}$ represent our estimates of interest and measure the association between each resource category and final course grade. We present our results in terms of odds-ratios, or a comparison of the likelihood of receiving an $\mathrm{A}$ or $\mathrm{B}$ versus a $\mathrm{C}$ in a given course. Thus, $\beta_{1}$ is the withinsemester estimate of how much a one-percentile increase in the use of course information resources changes the likelihood that a student receives an A or B versus a $C$ for a final course grade. The interpretations are the same for the other three resource types. While these estimates do not represent a causal link between resource use and final grades, we have reduced the bias in the estimates by adjusting for some potential confounding factors within the student background measures and semester fixed effects. Other unobserved factors may influence the associations between resource use and final grades.

In addition to the logistic regression model, we also estimate a multinomial logistic regression model for each course. In the multinomial model, each final grade category $(A, B, \operatorname{or} C)$ is a separate outcome. We are able compare differences in the association between course resources and the likelihood of receiving an A vs. B final grade with the likelihood of receiving a B vs. C final grade within the same model. The measures of resource use, covariates, and semester fixed-effects remain the same as in model 1.

\section{$4 \quad$ RESULTS}

\subsection{Descriptive Results}

We first describe the distribution of students and grades in courses over all semesters in Table 1 . The amount of available data is highly variable by course. For example, we have three semesters of data on CHEM 202, with only one course section per semester. At the opposite end of the spectrum, we have twelve semesters worth of data for ENGR 198, across which there were 81 individual course sections. We pooled together data across individual sections in each semester. Proportional to the number of semesters of data and sections of each course we examine are the total number of students for which we have information. These range from 754 students in CHEM 202 to 9,679 students in CHEM 101.

A descriptive examination of the grades in each course reveals that the proportion of students receiving different types of grades varies across courses. These range from a low of $20.0 \%$ of students receiving an A across all semesters of CHEM 101 to $54.6 \%$ of students in CHEM 202. For the most part, a sizable proportion of students receive a C grade in each course, with the exception of CHEM 202 and ENGR 198. We noticed that the grade distribution within each course is relatively consistent across semesters, enabling us to generalizing our results to future semesters. 
(2016). Improving early warning systems with categorized course resource usage. Journal of Learning Analytics, 3(3), 263-290. http://dx.doi.org/10.18608/jla.2016.33.13

Table 1. Final Grade Distribution of Students in STEM Courses

\begin{tabular}{rccrrrrr}
\hline Course & Semesters & $\begin{array}{c}\text { Course } \\
\text { Sections }\end{array}$ & $\begin{array}{r}\text { A, B, \& C } \\
\text { Students }\end{array}$ & $\begin{array}{r}\text { Students in } \\
\text { Analyses }\end{array}$ & $\begin{array}{c}\text { \% A Final } \\
\text { Grade }\end{array}$ & $\begin{array}{c}\text { \% B Final } \\
\text { Grade }\end{array}$ & $\begin{array}{c}\text { \% C Final } \\
\text { Grade }\end{array}$ \\
\hline CHEM 101 & 10 & 10 & 9,679 & 8,675 & 20.0 & 57.9 & 22.1 \\
CHEM 201 & 5 & 5 & 1,088 & 1,087 & 34.4 & 43.2 & 22.4 \\
CHEM 202 & 3 & 3 & 754 & 751 & 54.6 & 38.2 & 7.2 \\
ENGR 198 & 12 & 81 & 5,209 & 5,197 & 45.9 & 47.6 & 6.5 \\
ENGR 199 & 9 & 18 & 3,236 & 3,230 & 52.9 & 34.9 & 12.1 \\
PHYS 101 & 4 & 16 & 4,823 & 4,810 & 29.0 & 37.6 & 33.4 \\
PHYS 201 & 6 & 6 & 2,054 & 1,823 & 32.5 & 32.6 & 34.9 \\
\hline
\end{tabular}

Final grades represent the percentage of students receiving any version of a given letter grade (e.g., $A+, A, A-$ are " $A$ " students) across all semesters within a given course. Students in analyses represent those with no missing data for demographic and academic background information (see Appendix Table C.1 for full grade distribution).

We describe the demographic and academic background of students in the analyses by course in Table 2. Females compose approximately half of the students enrolled in first- and second-year chemistry courses but only about one-quarter of the students enrolled in these engineering or physics courses. The majority of students across all courses are U.S. citizens. Of the students taking the math placement exam, nearly $75 \%$ of students in chemistry courses and $90 \%$ of students in engineering or physics courses placed in the highest math course. Across semesters, students' mean semester GPA less the specific STEM course ranged from 3.07 to 3.39, roughly in line with STEM Academy expectations for students.

Table 2. Demographic and Academic Background of Students in STEM Courses

\begin{tabular}{rccccc}
\hline & & \multicolumn{2}{c}{ Citizenship } & & \\
\cline { 3 - 4 } Course & \% Female & $\begin{array}{c}\text { \% Perm-US } \\
\text { Resident }\end{array}$ & $\begin{array}{c}\text { \% Non-US } \\
\text { Resident }\end{array}$ & $\begin{array}{c}\text { \% Placed in } \\
\text { Calculus I } \\
\text { for 1st Term }\end{array}$ & $\begin{array}{c}\text { Mean } \\
\text { Sem. GPA } \\
\text { (less course) }\end{array}$ \\
\hline CHEM 101 & 44.8 & 3.1 & 3.4 & 72.1 & 3.11 \\
CHEM 201 & 51.7 & 5.7 & 4.4 & 78.8 & 3.39 \\
CHEM 202 & 53.3 & 4.9 & 2.0 & 76.0 & 3.27 \\
ENGR 198 & 25.9 & 3.1 & 7.3 & 93.0 & 3.07 \\
ENGR 199 & 26.7 & 3.2 & 7.6 & 89.0 & 3.11 \\
PHYS 101 & 28.9 & 2.7 & 6.1 & 92.5 & 3.26 \\
PHYS 201 & 20.2 & 3.2 & 6.5 & 92.7 & 3.28 \\
\hline
\end{tabular}

We next describe how the pattern of accessing resources in each category varies by final student grade across all semesters in Table 3. Instructors of each course will provide a different number of resources in the LMS for student use across semesters. These numbers vary highly both within (between each resource category) and across courses. The most important information from these descriptive results is how the means of resource accesses within any on course or category differ by final course grade. ${ }^{5}$

\footnotetext{
${ }^{5}$ We observe some large standard deviations of the number of resource accesses, indicative of students accessing the same resources multiple times in the LMS (as opposed to downloading once and saving). This factor, along with the changing number resources available to students across courses/semesters is why we use the percentile rank to measure student resource use.
} 
(2016). Improving early warning systems with categorized course resource usage. Journal of Learning Analytics, 3(3), 263-290.

http://dx.doi.org/10.18608/jla.2016.33.13

We see a general trend that the mean number of resource accesses across all courses in the categories of Course Information, Exam Preparation, and Assignment (with the exception of CHEM 201) resources is highest for A students with B students next and C students having the lowest means. In other words, there appears to be a positive association between course resource use and student final grade. There is one exception: for the Lecture resources, only about four of the seven courses follow the same positive trend between resource use and student final grade as with the other resource types.

Table 3. Mean Course Resource Hits by Final Grade

\begin{tabular}{|c|c|c|c|c|c|c|}
\hline \multirow[b]{2}{*}{ Course } & \multicolumn{3}{|c|}{ Course Information Resources } & \multicolumn{3}{|c|}{ Exam Preparation Resources } \\
\hline & A Grades & B Grades & C Grades & A Grades & B Grades & C Grades \\
\hline \multirow[t]{2}{*}{ CHEM 101} & 1.6 & 1.5 & 1.4 & 27.5 & 24.9 & 20.2 \\
\hline & {$[1.9]$} & {$[1.7]$} & {$[1.6]$} & [11.8] & {$[11.2]$} & {$[10.6]$} \\
\hline \multirow[t]{2}{*}{ CHEM 201} & 13.1 & 12.0 & 10.6 & 19.9 & 13.4 & 10.1 \\
\hline & {$[9.8]$} & {$[9.5]$} & {$[9.1]$} & {$[22.5]$} & {$[16.8]$} & {$[13.5]$} \\
\hline \multirow[t]{2}{*}{ CHEM 202} & 14.8 & 13.4 & 12.3 & NA & NA & NA \\
\hline & {$[9.9]$} & {$[11.0]$} & {$[13.5]$} & & & \\
\hline \multirow[t]{2}{*}{ ENGR 198} & 12.6 & 10.9 & 9.6 & 7.9 & 6.2 & 4.6 \\
\hline & [13.7] & [11.9] & [11.3] & {$[8.9]$} & {$[7.7]$} & {$[6.6]$} \\
\hline \multirow[t]{2}{*}{ ENGR 199} & 13.5 & 12.8 & 11.3 & 22.3 & 21.3 & 18.0 \\
\hline & [23.8] & {$[22.4]$} & [16.1] & {$[14.6]$} & {$[14.6]$} & {$[14.4]$} \\
\hline \multirow[t]{2}{*}{ PHYS 101} & 78.2 & 75.6 & 77.1 & 50.9 & 50.5 & 45.1 \\
\hline & {$[84.2]$} & [71.0] & {$[70.0]$} & {$[37.4]$} & [33.7] & [33.2] \\
\hline \multirow[t]{3}{*}{ PHYS 201} & 20.3 & 17.5 & 17.1 & 30.1 & 25.5 & 21.5 \\
\hline & [23.4] & [18.1] & [18.1] & [30.3] & {$[29.1]$} & {$[24.6]$} \\
\hline & \multicolumn{3}{|c|}{ Assignment-Related Resources } & \multicolumn{3}{|c|}{ Lecture-Related Resources } \\
\hline Course & A Grades & B Grades & C Grades & A Grades & B Grades & C Grades \\
\hline \multirow[t]{2}{*}{ CHEM 101} & 3.9 & 3.4 & 3.1 & 9.4 & 7.8 & 6.9 \\
\hline & {$[6.3]$} & {$[5.8]$} & {$[5.1]$} & {$[6.3]$} & {$[5.9]$} & {$[5.5]$} \\
\hline \multirow[t]{2}{*}{ CHEM 201} & 55.9 & 56.6 & 57.6 & 16.4 & 13.0 & 9.9 \\
\hline & [58.6] & [48.7] & [46.3] & [18.4] & [14.9] & [11.3] \\
\hline \multirow[t]{2}{*}{ CHEM 202} & 53.6 & 52.5 & 44.1 & 27.6 & 32.4 & 41.6 \\
\hline & [34.4] & [29.5] & [17.1] & [29.7] & [29.4] & [30.0] \\
\hline \multirow[t]{2}{*}{ ENGR 198} & 58.0 & 47.2 & 40.5 & 41.4 & 34.6 & 26.6 \\
\hline & [48.9] & [39.0] & [33.6] & [37.4] & [33.9] & [26.4] \\
\hline \multirow[t]{2}{*}{ ENGR 199} & 125.0 & 109.4 & 106.4 & 76.0 & 76.3 & 79.6 \\
\hline & [69.9] & [75.0] & [72.3] & [46.4] & {$[47.0]$} & {$[50.8]$} \\
\hline \multirow[t]{2}{*}{ PHYS 101} & 15.1 & 12.2 & 9.5 & 220.4 & 175.9 & 141.2 \\
\hline & {$[27.6]$} & [23.1] & [19.7] & [488.1] & [337.1] & [292.0] \\
\hline \multirow[t]{2}{*}{ PHYS 201} & NA & NA & NA & 31.3 & 24.3 & 27.5 \\
\hline & & & & [53.6] & [45.1] & [49.8] \\
\hline
\end{tabular}

Standard deviations in brackets. We denote where there are no resources in a category within a given course as "NA."

The current version of Student Explorer already uses percentile ranks for LMS course website page views because academic advisors are easily able to make sense of which students are accessing the course site frequently versus those who are not. 
(2016). Improving early warning systems with categorized course resource usage. Journal of Learning Analytics, 3(3), 263-290. http://dx.doi.org/10.18608/jla.2016.33.13

\subsection{Logistic and Multinomial Logistic Regression Results}

In Table 4, we display the estimates of the associations between course resource use by category and final grades for our logistic (A/B vs. C) and multinomial logistic (A vs. B and B vs. C) regression models.

Table 4. Logistic and Multinomial Logistic Regression Results

\begin{tabular}{clll}
\hline & \multicolumn{3}{c}{ Course Information Resources } \\
\cline { 2 - 4 } Course & A/B vs. C & A vs. B & B vs. C \\
\hline CHEM 101 & $0.996^{* * *}$ & 0.999 & 0.998 \\
CHEM 201 & $1.017^{* * *}$ & $1.006^{*}$ & $1.009^{* *}$ \\
CHEM 202 & 1.003 & 1.006 & 1.007 \\
ENGR 198 & 1.000 & 0.999 & 1.001 \\
ENGR 199 & 0.997 & $0.996^{*}$ & 0.999 \\
PHYS 101 & $0.994^{* * *}$ & 0.998 & $0.994^{* * *}$ \\
PHYS 201 & $0.996^{\sim}$ & 0.998 & 0.996
\end{tabular}

Assignment-Related Resources

\begin{tabular}{|c|c|c|c|c|c|c|}
\hline \multirow[b]{2}{*}{ Course } & & \\
\hline & A/B vs. C & A vs. B & B vs. C & A/B vs. C & A vs. $B$ & B vs. C \\
\hline CHEM 101 & 0.998 & 0.999 & $0.993 * * *$ & 1.000 & $1.004 * * *$ & 0.998 \\
\hline CHEM 201 & $0.982 *$ & $0.984 *$ & 0.987 & 0.999 & 0.999 & 1.005 \\
\hline CHEM 202 & $1.023^{* * *}$ & 1.003 & 1.011 & $0.978 * * *$ & $0.991 * *$ & $0.983 * *$ \\
\hline ENGR 198 & 1.001 & 1.002 & 0.998 & 1.001 & 1.002 & 1.004 \\
\hline ENGR 199 & 0.998 & $1.004^{* *}$ & $0.995^{*}$ & $0.992 * * *$ & $0.992 * * *$ & $0.994 *$ \\
\hline PHYS 101 & $1.007 * * *$ & $1.010 * * *$ & $1.005 * *$ & $0.995 * * *$ & $0.995 * * *$ & 0.999 \\
\hline PHYS 201 & NA & NA & NA & $0.985^{* * *}$ & 1.000 & $0.986 * * *$ \\
\hline
\end{tabular}

$p<0.100,{ }^{*} p<0.050,{ }^{* *} p<0.010,{ }^{* * *} p<0.001$. Results for the logistic regression interpreted as the odds of receiving either an $A$ or $B$ final grade versus a $C$ for each one-percentile point increase in rank relative to peers within each resource category in a given course. Results for the multinomial logistic regression interpreted in a similar manner, separately comparing the odds of receiving an A versus B or a B versus C final grade. In both models, we control for each student's sex, citizenship, first-term math placement, semester GPA, and a set of semester fixed effects. We denote where there are no resources in a category in a course as "NA." We estimated separate models for each course.

There is a positive and statistically significant $(p<0.05)$ association between increased use of exam preparation resources and final student grades in five of the seven courses. This means that as a student uses the exam preparation resources in the LMS to a greater degree compared to their peers in the course, we predict that a student is more likely to receive an A or B grade as opposed to in $\mathrm{C}$. The associations are greater for distinguishing between $B$ and $C$ students as opposed to $A$ and $B$ students, though the differences between A and B students are either positive or null. CHEM 202 does not have any exam preparation resources and in CHEM 201, the association is positive but not statistically significant.

For the lecture-related resources, there is a negative and statistically significant $(p<0.05)$ association between resource use and final grades in four of the seven courses. The association is null in the remaining three courses. In other words, for students who use lecture-related resources to a greater degree, we predict that they are more likely to earn a $\mathrm{C}$ final grade as opposed to an A or B. For the 
(2016). Improving early warning systems with categorized course resource usage. Journal of Learning Analytics, 3(3), 263-290.

http://dx.doi.org/10.18608/jla.2016.33.13

course information and assignment-related resources, we find more of a mixed pattern regarding the association between the greater use of resources and grades. The use of assignment-related resources distinguishes between A or B students and C students in CHEM 202, where there are no exam preparation resources.

The student demographic and academic background covariates serve as controls in our model to obtain less-biased estimates of the associations between course resources and final grades. Therefore, we do not focus on the estimates of these covariates and instead provide the full model estimates in Appendix Tables C.2 and C.3. ${ }^{6}$ More importantly, the magnitude and statistical significance of associations between exam preparation resources and final grades did not substantially change between models where we excluded and included the covariates (results available from authors upon request).

At first glance, these estimates appear small. For example, the estimate of exam preparation resources on grades in CHEM 101 suggests that for each one-percentile increase (relative to peers in the course) in the use of exam preparation resources, a student is 1.014 times as likely to receive an A or B instead of a C. Though the point estimate is small, it is important to note that this only reflects a one-percentile point increase in the use of exam preparation resources relative to peers. Substantial changes in a student's use of resources relative to their peers (e.g., improving by 10 percentile points) would result in the oddsratio slope estimate changing by percentile change's power (e.g., $1.014^{10}$, or 1.149 times as likely to receive an $\mathrm{A}$ or $\mathrm{B}$ vs. a C for each 10 percentile increase in using exam preparation resources). ${ }^{7}$

\section{DISCUSSION}

\subsection{Summary and Implications}

In our first research question, we asked, "What is the association between students' use of four types of course LMS resources and the likelihood that a student receives a final course grade of A or B in a core STEM course versus a C?" The results in this study indicate that increased use of exam-preparation resources is positively associated with final course grades across semesters when accounting for student demographic and academic covariates and semester fixed effects. In contrast, increased use of lecturerelated resources is negatively associated with final course grades. For course information and assignment-related resources, we found mixed (some positive, negative, and null) associations.

In our second research question, we asked, "Are there similarities or differences in the associations between students' course resource use based on type and final course grades across multiple courses?" We found that the positive association between exam-preparation resources and final course grades

\footnotetext{
${ }^{6}$ On average, females are less likely to earn an A or B (particularly an A) rather than a C than males; citizenship is not associated with grades, with the exception of non-US residents scoring higher in physics courses; higher semester GPAs are positively associated with final grade; and students not taking Calculus I or higher as their first-term math course term receive lower course grades.

${ }^{7}$ This is due to the exponential nature of reporting odds-ratios from the results of logistic regression.
} 
(2016). Improving early warning systems with categorized course resource usage. Journal of Learning Analytics, 3(3), 263-290. http://dx.doi.org/10.18608/jla.2016.33.13

held true in five of the six courses that used exam preparation materials. We observed the negative association between lecture-related resources and final grades in four of the seven courses (null in the other three).

Expanding on Macfadyen \& Dawson's (2010) early paper demonstrating that types of LMS activity are related to student course performance, our results provide information about the value of specific types of content that instructors make available to their students. This is particularly useful for large introductory courses where instructors do not typically utilize the interactive LMS features identified by Macfadyen and Dawson. Specifically, our data show that increased use of resources designed to support exam preparation is an important factor in student success in these seven core STEM courses. The framework we used to categorize resources allows for instructor variability in the specific nature of the resources within categories, while still affording the opportunity to investigate multiple courses and verify the results across a set of courses. We can therefore hypothesize beyond our specific data set that the use of resources related to exam preparation would be important across the majority of the core first- and second-year STEM courses. This finding is likely to be unsurprising - but reassuring - to instructors who take the time to provide these type of resources on their class sites.

While many studies of EWSs are focused on student retention (Jayaprakash et al., 2014), in this study we go beyond a binary pass/no-pass analysis (e.g., Fritz, 2016) to demonstrate important differences in LMS use between average and high achieving students. As most students in this university pass these core classes - indeed there were so few students with failing grades that we excluded them from our analysis - we were able to identify which kinds of LMS content were utilized more by the students with the highest grades. This is particularly important, as even high achieving students in these core courses are likely to experience a lower than expected grade (McKay, Miller, \& Tritz, 2012) and subsequently use these grades in the courses to make decisions about whether to major in a particular field (Rask, 2010). Given that attrition in STEM majors is highest in the first or second year of university (Seymour \& Hewitt, 1997), it is important that we help students be successful at levels to which they aspire, as dissatisfaction with academic performance is a likely factor in the decision to leave a STEM major.

For academic advisors, the visibility of resource use provided by the EWS allows them to identify how and when variability in "studenting skills" may need to be the focus of their intervention in order to promote successful student behaviours (Griffin, McGaw, \& Care, 2012). We can better illustrate how these results can influence advisor conversations with students when looking at performance through Student Explorer by considering a scenario of a hypothetical student. Several weeks into the course, the advisor observes this student has an overall course grade on the margin between a $B$ and $C$. This hypothetical student is also at the $25^{\text {th }}$ percentile (bottom quartile) of resource use compared to their classmates. As an actionable intervention, the advisor could suggest using more of the course's LMS resources. In particular, they may focus on resource categories historically shown to be associated with the likelihood of receiving a higher final grade, such as exam preparation resources. 
(2016). Improving early warning systems with categorized course resource usage. Journal of Learning Analytics, 3(3), 263-290. http://dx.doi.org/10.18608/jla.2016.33.13

We can use the results of our models to estimate how the student's likelihood of receiving a certain final grade would change if they increased their use of exam preparation resources. In Table 5 below, we present the change in likelihood of receiving a final grade if a hypothetical student were to change their use of exam resources from the $25^{\text {th }}$ percentile (bottom quartile) to the $50^{\text {th }}$ percentile (median).

\begin{tabular}{|c|c|c|c|}
\hline Course & $A / B$ vs. $C$ & A vs. $B$ & B vs. C \\
\hline CHEM 101 & 1.413 & 1.125 & 1.529 \\
\hline CHEM 201 & NS & 1.309 & NS \\
\hline CHEM 202 & NA & NA & NA \\
\hline ENGR 198 & 1.205 & 1.181 & 1.213 \\
\hline ENGR 199 & 1.159 & NS & 1.322 \\
\hline PHYS 101 & 1.127 & NS & 1.086 \\
\hline PHYS 201 & 1.357 & NS & 1.320 \\
\hline
\end{tabular}

Results interpreted as the odds of receiving a higher final grade for a student that increases their exam preparation resource use from the $25^{\text {th }}$ percentile to the $50^{\text {th }}$ percentile (median) in the class within a given semester. NA (not available) and NS (not significant at $5 \%$ from the model results) also displayed.

We predict that a student who begins using exam preparation resources to a greater degree will be anywhere from 1.13 to 1.41 times (based on course) as likely to receive an A or B as a C in the course than if they did not change their resource use patterns. On the margin of receiving a $B$ or a $C$, or the margin of receiving a "desirable" vs. "undesirable" outcome, the predicted increase in the likelihood of receiving a $B$ ranges from 1.09 to 1.53 times. These are meaningful patterns and estimates, whereby a small, yet targeted change in a student's behaviour could improve the likelihood of performing as desired in a course by 9 to 53\%. As discussed above, achieving a B versus $C$ grade (or even an A versus $B$ grade) may determine a student's decision about whether to continue in STEM, particularly for women and underrepresented minority students who are most likely to experience stereotype threat in these courses (Nguyen, \& Ryan, 2008).

Another important finding is that these results held across semesters. Although the overall content structure within a given entry-level course remains largely the same across semesters, the instructors and resources available to students may change with each offering. We would expect some content and resource changes to continue over time. However, an increase in the use of student-centred pedagogies in introductory STEM courses that rely less on a few high-stakes exams as the main determinant for the course grade may necessitate a shift away from the importance of using exam-preparation resources (e.g., Towns \& Grant, 1997). At first glance, changes across semesters to resources included in the LMS would seem problematic for incorporating resource use in an individualized, course-by-course manner into an EWS. However, our framework categorizes resources across courses, suggesting that system developers should incorporate simple mechanisms for instructors to designate category labels to each resource added to the course site. Making such labels visible to students could also help them to understand why and when to attend to various resources available on their course websites. 
(2016). Improving early warning systems with categorized course resource usage. Journal of Learning Analytics, 3(3), 263-290. http://dx.doi.org/10.18608/jla.2016.33.13

For the development of Student Explorer specifically, the categorization of resources allows developers to include data on specific resource use into the classification system across all STEM courses. Doing so would replace the count of general LMS site page views in the EWS algorithm. Specifically, perhaps most important for the application of these results to the STEM Academy is that students on the margin of receiving a " $\mathrm{B}$ " versus a " $\mathrm{C}$ " in the course can be distinguished by their use of exam preparation course resources. If the Student Explorer algorithm incorporated information about resource use, advisors could give students more targeted feedback to improve their habits, and potentially in turn, improve their grades. While the student's final grade is not the sole indicator of learning and various types of resources may support other aspects of knowledge building, the focus on course grade here reflects the STEM Academy's goal for all of their students to achieve at least a 3.0 overall grade point average.

\section{$5.2 \quad$ Limitations}

To build on this work, we need to be mindful of other approaches for aggregating course resource usage data provided by LMS event logs. Using percentile ranks allows for peer-to-peer comparisons and protects against outliers, but is not a perfect metric. Some students may use the resources as effectively as their peers but do so by downloading and saving the resource to their hard drives, which would represent one access in the event log without showing how many times they used that resource after the download. We will need to consider alternative metrics, including the proportion of materials used within each resource category, as well as a weighting scheme to reduce the influence of the number of accesses. In addition, not all courses may use materials falling directly into our resource categories (e.g., studio-based design courses), so working with faculty in non-STEM and advanced courses across disciplines will reveal ways to make our categorization scheme flexible while still supporting the success of this approach across different types of courses. As core STEM courses move away from primarily lecture-based instruction with multiple-choice exam assessment (Deslauriers, Schelew, \& Wieman, 2011), use of interactive features in the LMS may play a more prominent role in predicting student success (Macfadyen \& Dawson, 2010).

Our next steps involve expanding this analysis to refine our understanding of the relationship between course resource use and a student's developing grade over the course of a semester. For example, our results also suggest a negative association between the use of lecture-related resources and achieving higher grades. Because many types of lecture-related materials were captured as a single category (see Appendix B) we are unable to account for exactly why we observed this association. Some lecturerelated resources included video and audio recordings of the lectures as well the lecture overhead slides. It may be that some students are solely utilizing these materials instead of coming to class or perhaps focusing on reviewing lecture materials instead of testing their own knowledge with the exam preparation materials. Research on the impact of using lecture recordings in higher education is mixed, although there is some evidence that class attendance is an important mitigating factor ( $O^{\prime}$ Callaghan, Neumann, Jones, \& Creed, 2015). Unfortunately, course attendance is not captured by any of our campus systems, so we cannot add this variable into our analysis at this time. 
(2016). Improving early warning systems with categorized course resource usage. Journal of Learning Analytics, 3(3), 263-290. http://dx.doi.org/10.18608/jla.2016.33.13

In our future work we will also need to examine how the association between resource use and grades changes during the semester (i.e., before and after exams), in order to better focus advisors' recommendations to students. For example, we may find that students who use exam preparation resources after failing a test may show improved performance on the next test. We also plan to examine whether or not including course resource use into Student Explorer along with additional demographic or background data allows us to better classify at risk students. Linking students' online activity to other student data sources held by the university (e.g., admissions, registration, and financial aid data) presents new opportunities for predicting and intervening in student outcomes.

Finally, we note that aspects of our EWS and performance measures are specific to the context in which we conducted this study: a large, public, residential research university in the United States. Accordingly, future EWS research will need to continue to accommodate the specific context in which the courses are offered, considering both cultural and institutional factors related to practices in higher education.

\section{CONCLUSION}

In this study we have taken a specific student behaviour - use of different types of resources available in course LMSs - and generalized it across a series of courses representing typical introductory STEM courses offered at a large, residential research university in the United States. The results demonstrate that such resources often have explanatory power in predicting student success, particularly when the goal is to achieve at least a B grade in each course. Whether EWSs or other systems provide this information to advisors, instructors, or students, the consistency of associations we observe here is powerful for designing specific recommendations for helping students to understand how to succeed in these courses.

Instructors have long sought information about student use of the course resources that the instructor has curated and/or produced, particularly when instructors consider these resources to be valuable and take additional effort to create them. This study demonstrates that such resources can lead to student success in introductory STEM courses. We did not design our study to prescribe which kind of specific resources instructors should or should not include on their course sites, but rather to reveal how leveraging a resource's metadata thus becomes a powerful component to help describe and understand students' learning patterns and behaviours. Further research is needed to identify additional actionable data sources for building accurate and scalable Early Warning Systems and to better understand how such data can be best presented so that users of the data displays - advisors, instructors, and students - can take those appropriate actions. The question for designers and researchers of LA-based interventions is whether the data structures already available in logs generated by LMSs and other forms of technology-enabled learning allows for the investigation and definition of these associations so that targeted interventions can be implemented without imposing a unique structure for every course (or groups of courses) within a university. 
(2016). Improving early warning systems with categorized course resource usage. Journal of Learning Analytics, 3(3), 263-290. http://dx.doi.org/10.18608/jla.2016.33.13

\section{$7 \quad$ ACKNOWLEDGEMENTS}

This paper was supported by the Learning, Education \& Design (LED) Lab at the University of Michigan. We would like to acknowledge the contributions of Dr. Stephen Aguilar, Dr. Andrew Krumm, Dr. Kara Makara Fuller, Dr. Barry Fishman, Dr. Christopher Brooks, Amine Boudalia, and Gierad Laput. We are also grateful for the support and feedback from the director of the STEM Academy, Dr. Cinda-Sue Davis, and the STEM Academy advisors, Darryl Koch, Debbie Taylor, and Mark Jones. All opinions expressed in this paper represent those of the authors and not necessarily the institutions with which they are affiliated. All errors in this paper are solely the responsibility of the authors. For more information, please visit the LED Lab at http://digitaleducation.umich.edu/about-dei/learning-education-design-lab/

\section{REFERENCES}

Agudo-Peregrina, A. F., Iglesias-Pradas, S., Conde-Gonzalez, M. A., \& Hernandez-Garcia, A. (2014). Can we predict success from log data in VLEs? Classification of interactions for learning analytics and their relation with performance in VLE-supported F2F and online learning. Computers in Human Behavior, 31, 542-550. http://dx.doi.org/10.1016/j.chb.2013.05.031

Arnold, K. E. (2010). Signals: Applying academic analytics. Educause Quarterly, 33(10), 113-117.

Arnold, K. E., \& Pistilli, M. D. (2012). Course Signals at Purdue: Using learning analytics to increase student success. Proceedings of the $2^{\text {nd }}$ International Conference on Learning Analytics and Knowledge (LAK '12), 29 April-2 May 2012, Vancouver, BC, Canada (pp. 267-270). New York: ACM. https://doi.org/10.1145/2330601.2330666

Baughter, D., Varanelli, A., \& Weisbord, E. (2003). Student hits in an Internet-approved course: How can instructors use them and what do they mean? Decision Sciences Journal of Innovative Education, 1(2), 159-179. http://dx.doi.org/10.1111/j.1540-4609.2003.00016.x

Beck, H. P., \& Davidson, W. D. (2001). Establishing an early warning system: Predicting low grades in college students from survey of academic orientations scores. Research in Higher Education, 42(6), 709-723. http://dx.doi.org/10.1023/A:1012253527960

Beer, C., Jones, D., \& Clark, K. (2009). The indicators project identifying effective learning: Adoption, activity, grades and external factors. In R. J. Atkinson \& C. McBeath (Eds.), Same places, different spaces: Proceedings of ASCILITE Auckland 2009. $26^{\text {th }}$ Annual ASCILITE International Conference, 6-9 December 2009, Auckland, New Zealand (pp. 60-70). Auckland: ASCILITE. Retrieved from http://www.ascilite.org/conferences/auckland09/procs/beer.pdf

Braender, L. M., \& Naples, M. I. (2013). Evaluating the impact and determinants of student team performance: Using LMS and CATME data. Journal of Information Systems Education, 24(4), 281-288.

Braxton, J. A. (Ed.). (2000). Reworking the student departure puzzle. Nashville, TN: Vanderbilt University Press.

Campbell, J. P. (2007). Utilizing student data within the course management system to determine undergraduate student academic success: An exploratory study. Unpublished doctoral dissertation. Purdue University, Indiana. 
(2016). Improving early warning systems with categorized course resource usage. Journal of Learning Analytics, 3(3), 263-290.

http://dx.doi.org/10.18608/jla.2016.33.13

Campbell, J., DeBlois, P., \& Oblinger, D. (2007). Academic analytics: A new tool for a new era. Educause Review, 42(4), 40-57. Retrieved from http://net.educause.edu/ir/library/pdf/ERM0742.pdf

Campbell, J. P., \& Oblinger, D. G. (2007). Academic analytics [White paper]. Retrieved from https://net.educause.edu/ir/library/pdf/PUB6101.pdf

Carrell, S. E., Page, M. E., \& West, J. E. (2010). Sex and science: How professor gender perpetuates the gender gap. The Quarterly Journal of Economics, 125(3), 1101-1144. http://dx.doi.org/10.3386/w14959

Cobb, P., Confrey, J., diSessa, A., Lehrer, R., \& Schauble, L. (2003). Design experiments in educational research. Educational Researcher, 32(1), 9-13, 35-37. http://dx.doi.org/10.3102/0013189x032001009

Deslauriers, L., Schelew, E., \& Wieman, C. (2011). Improved learning in a large-enrollment physics class. Science, 332, 862-864. http://dx.doi.org/10.1126/science.1201783

Dringus, L. P. (2012). Learning analytics considered harmful. Journal of Asynchronous Learning Networks, 16(3), 87-100.

Duval, E. (2011). Attention please! Learning analytics for visualization and recommendation. Proceedings of the $1^{\text {st }}$ International Conference on Learning Analytics and Knowledge (LAK '11), 27 February1 March 2011, Banff, AB, Canada (pp. 9-17). New York: ACM. https://dx.doi.org/10.1145/2090116.2090118

Ferguson, R. (2012). Learning analytics: Drivers, developments, and challenges. International Journal of Technology Enhanced Learning, 4(5/6), 304-317. http://dx.doi.org/10.1504/IJTEL.2012.051816

Fritz, J. (2016). Using analytics to encourage student responsibility for learning and identify course designs that help. Unpublished doctoral dissertation. University of Maryland, Baltimore College. Retrieved from http://gradworks.umi.com/10/11/10118996.html.

Griffin, P., McGaw, B., \& Care, E. (2012). Assessment and teaching of 21st century skills. Dordrecht, Netherlands: Springer. http://dx.doi.org/10.1007/978-94-017-9395-7

Harrison, S., Villano, R., Lynch, G., \& Chen, G. (2015). Likelihood analysis of student enrollment outcomes using learning environment variables: A case study approach. Proceedings of the $5^{\text {th }}$ International Conference on Learning Analytics and Knowledge (LAK '15), 16-20 March 2015, Poughkeepsie, NY, USA (pp. 141-145). New York: ACM. https://dx.doi.org/10.1145/2723576.2723621

Hazari, Z., Tai, R. H., \& Sadler, P. M. (2007). Gender differences in introductory university physics performance: The influence of high school physics preparation and affective factors. Science Education, 91(6) 847-876. http://dx.doi.org/10.1002/sce.20223

Hu, Y., Lo, C., \& Shih, S. (2014). Developing early warning systems to predict students' online learning performance. Computers in Human Behavior, 36, 469-478. http://dx.doi.org/10.1016/j.chb.2014.04.002

Huberth, M., Chen, P., Tritz, J., \& McKay, T. A. (2015). Computer-tailored student support in introductory physics. PLOS ONE, 10(9), e0137001. http://dx.doi.org/10.1371/journal.pone.0137001 
(2016). Improving early warning systems with categorized course resource usage. Journal of Learning Analytics, 3(3), 263-290.

http://dx.doi.org/10.18608/jla.2016.33.13

Jayaprakash, S. M., Moody, E. W., Lauria, E. J., Regan, J. R., \& Baron, J. D. (2014). Early alert of academically at-risk students: An open source analytics initiative. Journal of Learning Analytics, 1(1), 6-47.

Johnson, L., Becker, S., Estrada, V., \& Freeman, A. (2014). Horizon report: 2014 higher education. Austin, TX: New Media Consortium.

Kost, L. E., Pollock, S. J., \& Finkelstein, N. D. (2009). Characterizing the gender gap in introductory physics. Physical Review Special Topics - Physics Education Research, 5(1), 1-14. https://dx.doi.org/10.1103/PhysRevSTPER.5.010101

Kovanović, V., Gašević, D., Dawson, S., Joksimović, S., Baker, R. S., \& Hatala, M. (2015). Penetrating the black box of time-on-task estimation. Proceedings of the $5^{\text {th }}$ International Conference on Learning Analytics and Knowledge (LAK '15), 16-20 March 2015, Poughkeepsie, NY, USA (pp. 184-193). New York: ACM. https://doi.org/10.1145/2723576.2723623

Krumm, A. E., Waddington, R. J., Teasley, S. D., \& Lonn, S. (2014). A learning management system-based early warning system for academic advising in undergraduate engineering. In J. Larusson \& B. White (Eds.), Learning analytics: From research to practice (pp. 103-122). New York: Springer. http://dx.doi.org/10.1007/978-1-4614-3305-7_6

Lonn, S., Teasley, S. D., \& Krumm, A. E. (2011). Who needs to do what where? Using learning management systems on residential vs. commuter campuses. Computers \& Education, 56(3), 642-649. http://dx.doi.org/10.1016/j.compedu.2010.10.006

Lonn, S., Aguilar, S. J., \& Teasley, S. D. (2015). Investigating student motivation in the context of a learning analytics intervention during a summer bridge program. Computers in Human Behavior, 47, 90-97. http://dx.doi.org/10.1016/j.chb.2014.07.013

Macfadyen, L. P., \& Dawson, S. (2010). Mining LMS data to develop an "early warning system" for educators: A proof of concept. Computers \& Education, 54(2), 588-599. http://dx.doi.org/10.1016/j.compedu.2009.09.008

May, M., George, S., \& Prévôt, P. (2011). TrAVis to enhance online tutoring and learning activities: Realtime visualization of students tracking data. Interactive Technology and Smart Education, 8(1), 52-69. http://dx.doi.org/10.1108/17415651111125513

McKay, T., Miller, K., \& Tritz, J. (2012, April). What to do with actionable intelligence: E2 Coach as an intervention engine. Proceedings of the $2^{\text {nd }}$ International Conference on Learning Analytics and Knowledge (LAK '12), 29 April-2 May 2012, Vancouver, BC, Canada (pp. 88-91). New York: ACM. https://dx.doi.org/10.1145/2330601.2330627

Morris, L. V., Finnegan, C., \& Wu, S. (2005). Tracking student behavior, persistence, and achievement in online courses. The Internet and Higher Education, 8(3), 221-231. http://dx.doi.org/10.1016/j.iheduc.2005.06.009

Nguyen, H. H. D., \& Ryan, A. M. (2008). Does stereotype threat affect test performance of minorities and women? A meta-analysis of experimental evidence. Journal of Applied Psychology, 93(6), 13141334. http://dx.doi.org/10.1037/a0012702 
(2016). Improving early warning systems with categorized course resource usage. Journal of Learning Analytics, 3(3), $263-290$.

http://dx.doi.org/10.18608/jla.2016.33.13

O'Callaghan, F. V., Neumann, D. L., Jones, L., \& Creed, P. A. (2015). The use of lecture recordings in higher education: A review of institutional, student, and lecturer data. Education and Information Technologies. http://dx.doi.org/10.1007/s10639-015-9451-z

Ornelas, F., Ordonez, C., \& Huston, D. (2014). Predicting student success: An application to community college data. Paper presented at the Annual Conference of the Association for Institutional Research, 27-30 May 2014, Orlando, FL.

Rask, K. (2010). Attrition in STEM fields at a liberal arts college: The importance of grades and precollegiate preferences. Economics of Education Review, 29(6), 892-900. http://dx.doi.org/10.1016/j.econedurev.2010.06.013

Seymour, E., \& Hewitt, N. M. (1997). Talking about leaving: Why undergraduates leave the sciences. Boulder, CO: Westview Press.

Sharkey, M., \& Ansari, M. (2014). Deconstruct and reconstruct: Using topic modeling on an analytics corpus. In K. Yacef \& H. Drachsler (Eds.), Workshop Proceedings of LAK 2014. Retrieved from http://ceur-ws.org/Vol-1137/lakdatachallenge2014_submission_1.pdf.

Siemens, G., \& Long, P. (2011). Penetrating the fog: Analytics in learning and education. EDUCAUSE Review, 46(5), 30.

SoLAR. (n.d.). About SoLAR. Retrieved from https://solaresearch.org/about/

Towns, M. H., \& Grant, E. R. (1997). I believe I will go out of this class actually knowing something: Cooperative learning activities in physical chemistry. Journal of Research in Science Teaching, 34(8), 819-835.

van Barneveld, A., Arnold, K. E., \& Campbell, J. P. (2012). Analytics in higher education: Establishing a common language. Educause Learning Initiative, 1, 1-11.

Waddington, R. J., \& Nam, S. J. (2014). Practice exams make perfect: Incorporating course resource use into an early warning system. Proceedings of the $4^{\text {th }}$ International Conference on Learning Analytics and Knowledge (LAK '14), 24-28 March 2014, Indianapolis, IN, USA (pp. 188-192). New York: ACM. https://dx.doi.org/10.1145/2567574.2567623

Zhao, C.-M., Kuh, G. D., \& Carini, R. M. (2005). A comparison of international student and American student engagement in effective educational practices. The Journal of Higher Education, 76(2), 209-231. 
(2016). Improving early warning systems with categorized course resource usage. Journal of Learning Analytics, 3(3), 263-290. http://dx.doi.org/10.18608/jla.2016.33.13

\section{Appendix A. Description of Core STEM Courses Included in Analyses}

\begin{tabular}{|c|c|}
\hline Course & Description \\
\hline CHEM 101 & $\begin{array}{l}\text { General Chemistry Lab 1. A "course designed around student interdependence and inter-group } \\
\text { collaboration" where "students perform chemistry experiments in a group learning } \\
\text { environment." The primary objectives of the course include encouraging scientific and critical } \\
\text { thinking through teamwork, experiencing how experimental results demonstrate various } \\
\text { chemical principles, and engaging students in the process of using the scientific method and } \\
\text { reasoning. These objectives suggest that success in the course will be central to success in future } \\
\text { STEM courses. }\end{array}$ \\
\hline
\end{tabular}

CHEM 201 Structure and Relativity 2. Continuation of the introduction to organic chemistry course. The course must be taken concurrently with CHEM 202. Students get further practice in applying the major concepts of chemistry to predicting the physical and chemical properties of organic compounds, including macromolecules, both synthetic and biological. Course exams will test students' ability to project and apply the broad concepts to new and unfamiliar situations.

CHEM 202 Synthesis and Characterization of Organic Compounds. Students participate in planning exactly (Lab) what they are going to do in the laboratory by being given general goals and directions that have to be adapted to fit the specific project they will be working on. They use microscale equipment, which requires them to develop manual dexterity and care in working in the laboratory. They also evaluate the results of their experiments by checking for identity and purity using various chromatographic and spectroscopic methods. Must be taken concurrently with CHEM 201.

ENGR 198 Introduction to Engineering. Focused team projects dealing with technical, economic, safety, (Project) environmental, and social aspects of a real-world engineering problem. Written, oral, and visual communication required within the engineering profession; reporting on the team engineering projects. The role of the engineer in society; engineering ethics. Organization and skills for effective teams.

ENGR 199 Introduction to Computers and Programming. This course introduces first-year students to the concept of an algorithm: a well-defined set of instructions that achieve a particular goal. Constructing an algorithm for a given purpose is a fundamental form of engineering design task, and developing computer programs is part of almost every modern engineering project. Students learn how to conceptualize algorithms for solving engineering problems and express them in the programming languages MATLAB and C++.

PHYS 101 General Physics 1. This course offers an introduction to classical mechanics, the physics of motion. Topics include: vectors, linear motion, projectiles, relative velocity and acceleration, circular motion, Newton's laws, particle dynamics, work and energy, linear momentum, torque, angular momentum, gravitation, planetary motion, fluid statics and dynamics, simple harmonic motion, waves and sound. Should be taken concurrently with the corresponding lab course.

PHYS 201 General Physics 2. This course covers topics in electricity and magnetism: charge, Coulomb's law, electric fields, Gauss' law, electric potential, capacitors and dielectrics, current and resistance, EMF and circuits, magnetic fields, Biot-Savart law, Amperes law, Faraday's Law of Induction, and simple AC circuits. Should be taken concurrently with the corresponding lab course. 
(2016). Improving early warning systems with categorized course resource usage. Journal of Learning Analytics, 3(3), 263-290. http://dx.doi.org/10.18608/jla.2016.33.13

\section{Appendix B. Classification of Course Resources}

We completed the process of categorizing course resources by labelling each resource manually. We used a probabilistic model to guide this process, which suggested the most likely resource category based on the filename. Initially, we built this model based categorizing resources from a previous study on CHEM 101 (Waddington \& Nam, 2014). We first separated file names from each course's site by spaces, punctuation, or any other non-alpha-numeric characters to build a course resources corpus. We used the frequencies of corpus elements to train the probability model to infer the resource category of given file name. Then, we applied this model to another course's resource list and manually corrected any errors. We then reused the corrected results as a training set to update the model and applied the model to predict the resource category of another course's unlabelled resource list. We conducted this iterative process for each course, which in the end saved the amount of time needed to label the vast amount of course resources manually that differ across courses and semesters. In Table B.1., we display examples of the types of resources within each resource category.

Table B.1. Categories of LMS Course Resources

\begin{tabular}{ll}
\hline \multicolumn{1}{c}{ Category } & \multicolumn{1}{c}{ Examples of Resources } \\
\hline Course Information & $\begin{array}{l}\text { Schedules, Course Website, Announcements, Syllabus, Instructor Information, } \\
\text { Course Grades }\end{array}$ \\
Lecture Materials & $\begin{array}{l}\text { Lecture Notes, Discussion Tools, General Resources, Online Learning } \\
\text { Resources, Lecture Audio Recordings, Cross Discipline Learning Objects }\end{array}$ \\
Assignments & Experiments, Pre-labs, Team Assignments, Team Report Forms, Discussion \\
Exam Preparation & Sample Exams, Exam Review \\
\hline
\end{tabular}


(2016). Improving early warning systems with categorized course resource usage. Journal of Learning Analytics, 3(3), 263-290. http://dx.doi.org/10.18608/jla.2016.33.13

\section{Appendix C. Additional Tables of Results}

Table C.1. Full Final Grade Distribution of Students in STEM Courses

\begin{tabular}{lcccccccc}
\hline & & \multicolumn{7}{c}{ Percentage across All Semesters } \\
\cline { 5 - 8 } Course & $\begin{array}{c}\text { Total } \\
\text { Students }\end{array}$ & $\begin{array}{c}\text { Excluded } \\
\text { Students }\end{array}$ & $\begin{array}{c}\text { A Final } \\
\text { Grade }\end{array}$ & $\begin{array}{c}\text { B Final } \\
\text { Grade }\end{array}$ & $\begin{array}{c}\text { C Final } \\
\text { Grade }\end{array}$ & $\begin{array}{c}\text { D Final } \\
\text { Grade }\end{array}$ & $\begin{array}{c}\text { F Final } \\
\text { Grade }\end{array}$ & $\begin{array}{c}\text { W/I Final } \\
\text { Grade }\end{array}$ \\
\hline CHEM 101 & 9,958 & 279 & 19.8 & 56.1 & 21.3 & 0.5 & 0.0 & 1.6 \\
CHEM 201 & 1,241 & 153 & 30.1 & 38.0 & 19.6 & 4.2 & 0.0 & 4.2 \\
CHEM 202 & 767 & 13 & 53.7 & 37.5 & 7.0 & 0.1 & 0.0 & 1.3 \\
ENGR 198 & 5,271 & 62 & 44.8 & 46.9 & 6.5 & 0.6 & 0.0 & 0.9 \\
ENGR 199 & 3,470 & 234 & 49.5 & 32.6 & 11.4 & 2.0 & 0.0 & 2.6 \\
PHYS 101 & 5,481 & 658 & 25.5 & 33.1 & 29.3 & 4.2 & 0.0 & 1.7 \\
PHYS 201 & 2,249 & 195 & 29.4 & 30.2 & 31.7 & 3.6 & 0.0 & 3.0 \\
\hline
\end{tabular}

Total students represent the number of students enrolled in the course across semesters as per registrar records. Excluded students represent those students with grade $\mathrm{E}$ or Pass/Fail cases. Final grades represent the percentage of students receiving any version of a given letter grade (e.g., $A+, A, A-$ are " $A$ " students).

Table C.2. Full Results from Logistic Regression Models

\begin{tabular}{llllllll}
\hline \multicolumn{1}{c}{ Variables } & CHEM & CHEM & CHEM & ENGR & ENGR & PHYS & PHYS \\
& $\mathbf{1 0 1}$ & $\mathbf{2 0 1}$ & $\mathbf{2 0 2}$ & $\mathbf{1 9 8}$ & $\mathbf{1 9 9}$ & $\mathbf{1 0 1}$ & $\mathbf{2 0 1}$ \\
\hline Course Info Res. & $0.996^{* * *}$ & $1.017^{* * *}$ & 1.003 & 1.000 & 0.997 & $0.994^{* * *}$ & $0.996^{\sim}$ \\
Exam Prep Res. & $1.014^{* * *}$ & 1.004 & NA & $1.007^{* * *}$ & $1.006^{* *}$ & $1.005^{* * *}$ & $1.012^{* * *}$ \\
Assignment Res. & 0.998 & $0.982^{*}$ & $1.023^{* *}$ & 1.001 & 0.998 & $1.007^{* * *}$ & NA \\
Lecture Res. & 1.000 & 0.999 & $0.978^{* * *}$ & 1.001 & $0.992^{* * *}$ & $0.995^{* * *}$ & $0.985^{* * *}$ \\
Female & $0.873^{* *}$ & $0.677^{*}$ & 1.207 & $1.314^{*}$ & $0.821^{\sim}$ & $0.560^{*}$ & $0.712^{*}$ \\
Perm. Resident & 1.216 & 1.041 & 1.166 & 0.786 & 1.182 & 1.040 & 0.893 \\
Non-Resident & 1.021 & 0.861 & 1.762 & $0.517^{* * *}$ & 0.895 & $3.084^{* * *}$ & $3.542^{* * *}$ \\
Semester GPA & $10.311^{* * *}$ & $6.773^{* * *}$ & $8.235^{* * *}$ & $4.644^{* * *}$ & $6.269^{* * *}$ & $10.460^{* * *}$ & $16.373^{* * *}$ \\
No Calc I+ Place. & $0.673^{* * *}$ & $0.570^{* *}$ & $0.593^{*}$ & $0.464^{* * *}$ & $0.572^{* * *}$ & $0.509^{* * *}$ & $0.425^{* * *}$ \\
No Place. Test & $0.453^{* * *}$ & $0.387^{* *}$ & $0.388^{*}$ & $0.357^{* *}$ & $0.078^{* * *}$ & $0.239^{* * *}$ & NA \\
\hline
\end{tabular}

$\mathrm{p}<0.100, * p<0.050, * * p<0.010, * * * p<0.001$. Results for the logistic regression interpreted as the odds of receiving a final grade of A versus B versus C for each variable. We denote where there are no resources in a category in a course as "NA." We estimated separate models for each course. 
(2016). Improving early warning systems with categorized course resource usage. Journal of Learning Analytics, 3(3), 263-290. http://dx.doi.org/10.18608/jla.2016.33.13

Table C.3. Full Results from Multinomial Logistic Regression Models

\begin{tabular}{|c|c|c|c|c|c|c|c|}
\hline \multicolumn{8}{|c|}{ A vs. B Final Grades } \\
\hline Variables & $\begin{array}{c}\text { CHEM } \\
101 \\
\end{array}$ & $\begin{array}{l}\text { CHEM } \\
201 \\
\end{array}$ & $\begin{array}{l}\text { CHEM } \\
202 \\
\end{array}$ & $\begin{array}{c}\text { ENGR } \\
198 \\
\end{array}$ & $\begin{array}{c}\text { ENGR } \\
199 \\
\end{array}$ & $\begin{array}{c}\text { PHYS } \\
101 \\
\end{array}$ & $\begin{array}{l}\text { PHYS } \\
201 \\
\end{array}$ \\
\hline Course Info Res. & 0.998 & $1.006^{*}$ & 1.006 & 0.999 & $0.996^{*}$ & 0.998 & 0.999 \\
\hline Exam Prep Res. & $1.005^{* * *}$ & $1.011 * * *$ & NA & $1.007 * * *$ & $1.003^{\sim}$ & 0.998 & 1.002 \\
\hline Assignment Res. & 0.999 & $0.984^{*}$ & 1.003 & 1.002 & $1.004 * *$ & $1.010 * * *$ & NA \\
\hline Lecture Res. & $1.004 * * *$ & 0.999 & $0.991 * *$ & 1.002 & $0.992 * * *$ & $0.995 * * *$ & 0.999 \\
\hline Female & $1.178 * *$ & $0.613^{* *}$ & 0.928 & $1.667 * * *$ & $0.683 * * *$ & $0.623 * * *$ & $0.539 * * *$ \\
\hline Perm. Resident & 1.282 & 0.578 & 1.084 & 0.950 & 0.715 & 1.013 & 1.561 \\
\hline Non-Resident & $1.743 * * *$ & 1.229 & 1.021 & $0.810^{\sim}$ & $1.535^{*}$ & $3.788 * * *$ & $3.778 * * *$ \\
\hline Semester GPA & $21.667 * * *$ & $14.400 * * *$ & $8.903 * * *$ & $4.452 * * *$ & $7.239 * * *$ & $14.294^{* * *}$ & $15.493 * * *$ \\
\hline No Calc I+ Place. & $0.710^{* * *}$ & $0.616^{*}$ & $0.605^{*}$ & $0.573 * * *$ & $0.593 * * *$ & 0.599* & 1.109 \\
\hline No Place. Test & $0.515^{* * *}$ & $0.243^{*}$ & $0.386^{*}$ & $0.247^{*}$ & $0.204^{*}$ & 0.228 & NA \\
\hline \multicolumn{8}{|c|}{ B vs. C Final Grades } \\
\hline Variables & $\begin{array}{c}\text { CHEM } \\
101\end{array}$ & $\begin{array}{l}\text { CHEM } \\
201\end{array}$ & $\begin{array}{l}\text { CHEM } \\
202\end{array}$ & $\begin{array}{c}\text { ENGR } \\
198\end{array}$ & $\begin{array}{c}\text { ENGR } \\
199\end{array}$ & $\begin{array}{l}\text { PHYS } \\
101\end{array}$ & $\begin{array}{l}\text { PHYS } \\
201\end{array}$ \\
\hline Course Info Res. & 0.998 & $1.009 * *$ & 1.007 & 1.001 & 0.999 & $0.994 * * *$ & 0.997 \\
\hline Exam Prep Res. & $1.017^{* * *}$ & 1.003 & NA & $1.008 * *$ & $1.011^{* * *}$ & $1.003^{*}$ & $1.010 * *$ \\
\hline Assignment Res. & $0.994 * * *$ & 0.987 & 1.011 & 0.998 & $0.995^{*}$ & $1.005^{* *}$ & NA \\
\hline Lecture Res. & 0.998 & 1.005 & $0.983 * * *$ & 1.004 & $0.994^{*}$ & 0.999 & $0.988 * * *$ \\
\hline Female & $0.841 * *$ & 0.836 & 1.129 & 1.201 & 0.971 & $0.584 * * *$ & 0.793 \\
\hline Perm. Resident & 1.221 & 1.103 & 0.682 & 0.753 & 1.314 & 1.046 & $0.560^{\sim}$ \\
\hline Non-Resident & 1.161 & 0.804 & NA & $0.488 * * *$ & 0.663 & $2.014 * * *$ & $2.247 * *$ \\
\hline Semester GPA & $6.120 * * *$ & $4.728 * * *$ & $3.942 * * *$ & $3.184^{* * *}$ & $2.793 * * *$ & $5.185^{* * *}$ & $5.547 * * *$ \\
\hline No Calc I+ Place. & $0.719 * * *$ & $0.521 * * *$ & 0.747 & $0.568 * * *$ & $0.682^{*}$ & $0.521 * * *$ & $0.441 * * *$ \\
\hline No Place. Test & $0.534 * * *$ & $0.367 * * *$ & 0.760 & $0.330 * * *$ & $0.167 * * *$ & 0.498 & NA \\
\hline
\end{tabular}


(2016). Improving early warning systems with categorized course resource usage. Journal of Learning Analytics, 3(3), 263-290. http://dx.doi.org/10.18608/jla.2016.33.13

Table C.4. Full Results from Multinomial Logistic Regression Models (D \& F Students Included)

\begin{tabular}{|c|c|c|c|c|c|c|c|}
\hline \multicolumn{8}{|c|}{ A vs. B Final Grades } \\
\hline Variables & $\begin{array}{c}\text { CHEM } \\
101\end{array}$ & $\begin{array}{l}\text { CHEM } \\
201\end{array}$ & $\begin{array}{l}\text { CHEM } \\
202\end{array}$ & $\begin{array}{c}\text { ENGR } \\
198\end{array}$ & $\begin{array}{c}\text { ENGR } \\
199\end{array}$ & $\begin{array}{l}\text { PHYS } \\
101\end{array}$ & $\begin{array}{l}\text { PHYS } \\
201\end{array}$ \\
\hline Course Info Res. & 0.998 & $1.006 *$ & 1.006 & 0.999 & $0.996^{*}$ & 0.998 & 0.998 \\
\hline Exam Prep Res. & $1.005^{* * *}$ & $1.011^{* * *}$ & NA & $1.007 * * *$ & $1.003^{\sim}$ & 0.998 & 1.003 \\
\hline Assignment Res. & 0.999 & $0.984^{*}$ & 1.003 & 1.002 & $1.005^{* *}$ & $1.010 * * *$ & NA \\
\hline Lecture Res. & $1.004^{* * *}$ & 0.999 & $0.991 * *$ & 1.002 & $0.992 * * *$ & $0.995 * * *$ & 1.000 \\
\hline Female & $1.226^{* *}$ & $0.612^{* *}$ & 0.928 & $1.667 * * *$ & $0.684^{* * *}$ & $0.617^{* * *}$ & $0.543 * * *$ \\
\hline Perm. Resident & 1.155 & 0.583 & 1.083 & 0.933 & 0.737 & 1.002 & 1.724 \\
\hline Non-Resident & $1.651 * *$ & 1.203 & 1.021 & $0.813^{\sim}$ & $1.534^{*}$ & $3.799 * * *$ & $3.848 * * *$ \\
\hline Semester GPA & $23.379 * * *$ & $14.422 * * *$ & $8.903 * * *$ & $4.452 * * *$ & $7.138 * * *$ & $13.949 * * *$ & $14.919 * * *$ \\
\hline No Calc I+ Place. & $0.714^{* * *}$ & $0.623^{*}$ & $0.605^{*}$ & $0.571^{* * *}$ & $0.592 * * *$ & $0.607^{*}$ & 1.015 \\
\hline No Place. Test & $0.490 * * *$ & $0.244^{*}$ & $0.386^{*}$ & $0.248^{*}$ & $0.206^{*}$ & 0.232 & NA \\
\hline \multicolumn{8}{|c|}{ B vs. C, D, or F Final Grades } \\
\hline \multirow{2}{*}{ Variables } & CHEM & CHEM & CHEM & ENGR & ENGR & PHYS & PHYS \\
\hline & 101 & 201 & 202 & 198 & 199 & 101 & 201 \\
\hline Course Info Res. & $0.998^{\sim}$ & $1.010 * *$ & 1.007 & 1.001 & 1.000 & $0.994 * * *$ & 0.996 \\
\hline Exam Prep Res. & $1.017 * * *$ & 1.002 & NA & $1.008 * *$ & $1.013^{* * *}$ & $1.004 *$ & $1.012 * * *$ \\
\hline Assignment Res. & $0.993 * * *$ & 0.989 & 1.011 & 0.999 & $0.995^{*}$ & $1.005^{* *}$ & NA \\
\hline Lecture Res. & 0.998 & 1.004 & $0.983 * * *$ & 1.004 & $0.995^{*}$ & 0.998 & $0.985^{* * *}$ \\
\hline Female & $0.855^{*}$ & 0.805 & 1.129 & 1.255 & 0.987 & $0.569 * * *$ & 0.754 \\
\hline Perm. Resident & 1.124 & 1.121 & 0.682 & 0.675 & 1.199 & 1.123 & $0.559^{\sim}$ \\
\hline Non-Resident & 1.130 & 0.750 & NA & $0.447 * * *$ & 0.701 & $1.791^{* *}$ & $2.631 * *$ \\
\hline Semester GPA & $6.382 * * *$ & $5.014 * * *$ & $3.944 * * *$ & $3.307 * * *$ & $3.045^{* * *}$ & $6.046 * * *$ & $6.042 * * *$ \\
\hline No Calc I+ Place. & $0.683 * * *$ & $0.511^{* * *}$ & 0.747 & $0.596 * * *$ & $0.714^{*}$ & $0.512 * * *$ & $0.425^{* * *}$ \\
\hline No Place. Test & $0.516 * * *$ & $0.384^{* *}$ & 0.759 & $0.339 * *$ & $0.165^{* * *}$ & 0.487 & NA \\
\hline
\end{tabular}

